Review

\title{
Osteoporosis in Postmenopausal Women with Breast Cancer
}

Jacqueline Lamond, Charles L. Shapiro *

Dubin Breast Cancer, Icahn School of Medicine at Mt Sinai, New York, NY 10029, US; E-Mails: Jacqueline.Lamond@mountsinai.org; Charles.shapiro@mssm.edu

* Correspondence: Charles L. Shapiro; E-Mail: Charles.shapiro@mssm.edu

Academic Editor: Ray Marks

Special Issue: Osteoporosis in the Elderly

\section{OBM Geriatrics}

2021, volume 5, issue 2

doi:10.21926/obm.geriatr.2102173
Received: December 07, 2020

Accepted: June 21, 2021

Published: June 30, 2021

\begin{abstract}
Breast cancer and osteoporosis are both diseases of aging. The "one in eight" lifetime risks of breast cancer occur primarily in the sixth, seventh, eighth, and ninth decades of life. One-third of postmenopausal women will experience an osteoporotic fracture. It is the coalescence of osteoporosis, breast cancer, and breast cancer treatments that, in some cases, increases the risks of osteoporotic fracture. That makes it imperative to assess risk factors, screen, and prevent or treat osteoporosis in postmenopausal women with breast cancer. Osteoporosis is primarily a genetic disease with a few modifiable risk factors. These risk factors include greater than two to three alcoholic drinks per day, current smoking, and decreased physical activity. The standard screening tool for osteoporosis is dual-energy $x$-ray absorptiometry (DXA) that gives a readout of T-scores of the lumbar spine, total hip, and femoral neck. The T-score is the number of standard deviations (SD) above or below the mean bone mineral density (BMD) of an average young adult of the same sex. For every SD below the mean BMD, the fracture risks double. Osteoporosis prevention and treatment do not differ in women with or without breast cancer. The difference is in breast cancer treatments, such as aromatase inhibitors (Al), which cause two to three-fold higher bone loss than average postmenopausal bone loss. Two classes of drugs for osteoporosis are oral and intravenous (iv) bisphosphonates and the receptor activator of nuclear factor kappa B ligand (RANKL) ligand inhibitor, subcutaneous (sc)
\end{abstract}

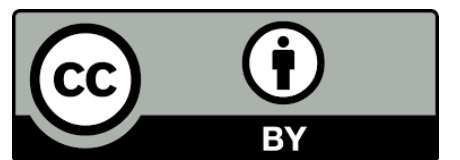

(C) 2021 by the author. This is an open access article distributed under the conditions of the Creative Commons by Attribution License, which permits unrestricted use, distribution, and reproduction in any medium or format, provided the original work is correctly cited. 
denosumab. All three prevent bone loss and reduce the likelihood of fragility fractures. The treatment choice depends upon patient and provider preferences, specific contraindications (e.g., renal insufficiency), compliance, and costs. Despite guidelines and algorithms for Alinduced bone loss, the screening and treatment of osteoporosis remain suboptimal in postmenopausal women with breast cancer.

\section{Keywords}

Osteoporosis; breast cancer; postmenopausal women

\section{Introduction}

The number of cancer survivors over age 65 years of age is increasing (Figure 1). By the year 2040, there will be 26 million cancer survivors in total. Osteoporosis is also a disease of aging and affects nearly 200 million individuals worldwide. One-third of postmenopausal women will experience an osteoporotic fracture. These fractures cause morbidity, mortality, economic impact and possibly are preventable.

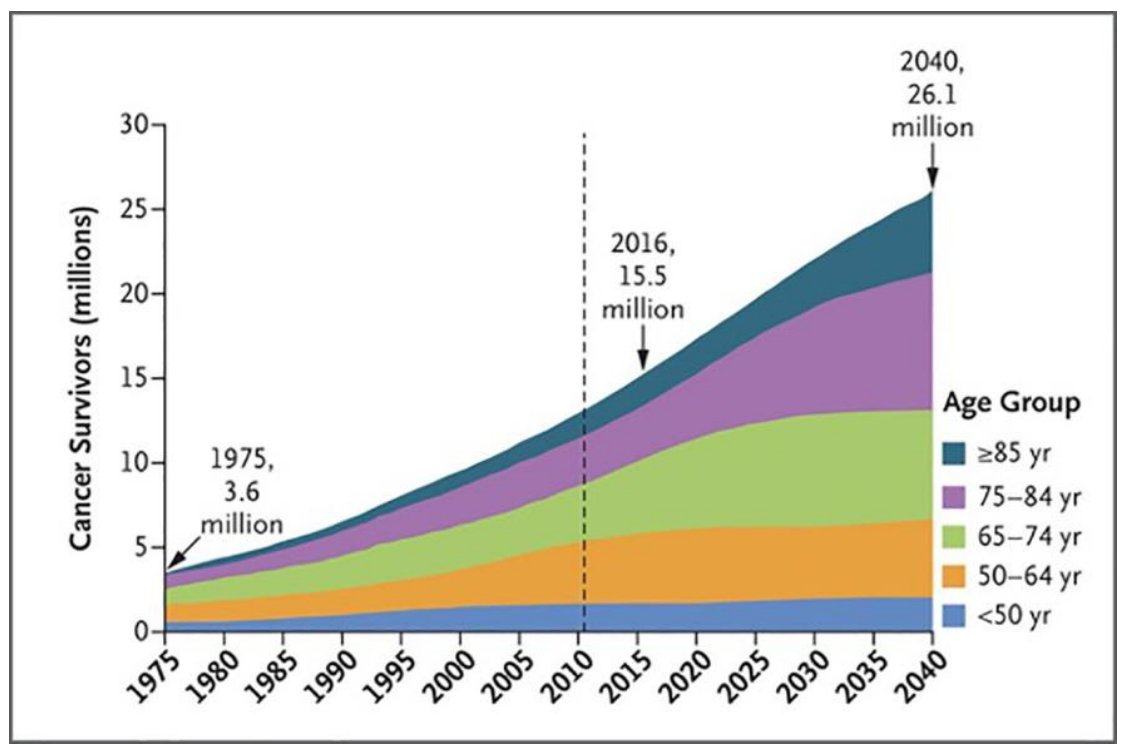

Figure 1 Cancer Survivorship over Time. The majority of cancer survivors now and in the future will be over the age the 65 years.

Bone loss and osteoporosis are commonly long-term (occurring during treatment and extending after treatment) and late-term (occurring after active treatment) adverse effects of breast cancer treatments [1, 2]. Postmenopausal women with breast cancer treated with aromatase inhibitors (Als) are at greater risk of developing osteoporosis [2]. Al-induced bone loss occurs at a rate of two to three-fold higher than that of a healthy postmenopausal woman or one to two-fold-higher than postmenopausal women taking tamoxifen. As breast cancer survivors continue to live longer, the risk for developing osteoporosis and subsequent fractures also increases. Appropriate identification of the risk factors associated with osteoporosis, the diagnosis, and management of the disease is critical in mitigating bone loss and fractures and improving overall health outcomes. 


\section{Bone Remodelling and Osteoporosis}

Bone is a dynamic tissue in a constant state of remodelling. Remodelling occurs in discrete areas of bone called remodelling units. Within the remodelling unit, there are three types of cells, osteoclasts, osteoblasts, and osteocytes. These three cells are responsible for bone resorption and new bone formation, respectively (Figure 2). The osteocyte is the master regulator of the bone remodelling unit. The osteocytes release RANKL and other osteoclastic cytokines (i.e., interleukin (IL)-1, IL-6, IL-7, IL-8, and IL-11) responsible for osteoclast differentiation and bone resorption [3]. Osteoprotegerin (OPG), also secreted by osteocyte, serves as a decoy receptor for RANKL and, in effect, decreases osteoclast activation and promoting new bone formation. Also, the osteocyte secretes sclerostin. Sclerostin suppresses Wnt signalling, which is critical for bone formation. The ratio between RANKL and OPG governs bone resorption and new bone formation in normal remodelling and bone loss to normal aging, menopause, and Als. (For a more extensive discussion of the osteocyte, see reviews by Creecy [4] and Kitaura [5]).

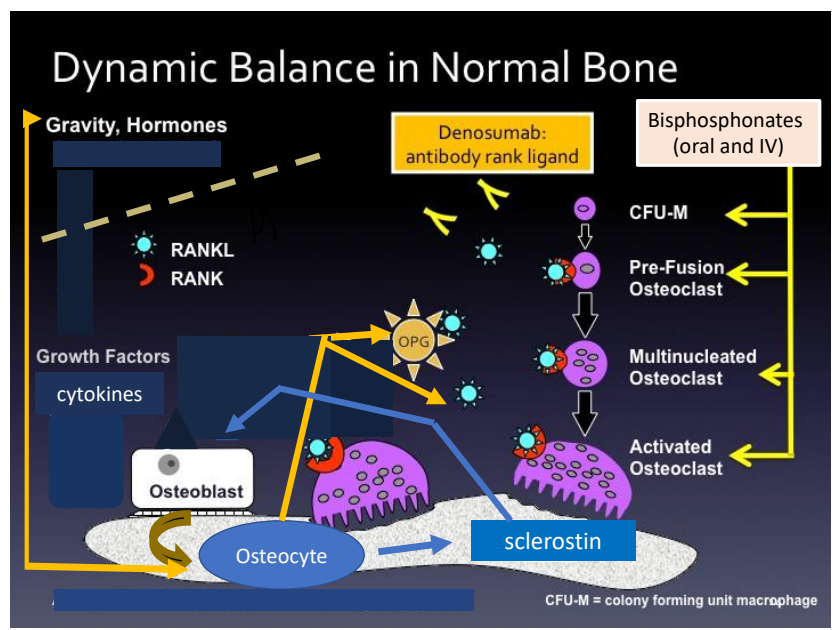

Figure 2 The Dynamic Balance of Bone Resorption and New Bone Formation. Two levels of regulation govern bone resorption and new bone formation. The Marco level is the effects of gravity, the mechanical stress and stains of activities of daily living, and systemic hormones including calcium-regulating hormones (parathyroid, calcitonin, and calcitriol), sex steroid hormones (estrogen and testosterone), and others (growth and insulin-like growth factor, thyroid hormones, and cortisol). At the Micro level is the dynamic interplay of osteoblasts, which cause new bone formation, osteoclasts that resorb bone, and osteocytes. The osteocytes are the master regulator cells secreting both receptor activator of nuclear factor-KB ligand (RANKL) and osteoprotegerin (OPG) of the TNF receptor superfamily [6]. RANKL binds to the Rank receptor and causes osteoclast precursor cells (derived from hematopoietic cells) to differentiate into mature osteoclasts and resorb bone. OPG acts as a decoy receptor for RANKL and causes inhibition of bone resorption and new bone formation. Also, osteocytes secrete sclerostin that inhibits osteoblastic new bone formation and stimulating bone resorption by secreting RANKL. Zoledronic acid (ZA) is an osteoclast inhibitor. In contrast, denosumab (DEN) is a monoclonal antibody directed against RANKL. Both drugs inhibit osteoclastic functions from resorbing bone and for preventing or treating osteoporosis. 
The remodelling process of bone involves four overlapping stages. The first stage is the initiation of bone remodelling at a specific site. The second involves bone resorption by osteoclasts and the recruitment of mesenchymal stem cells that are the origins of osteoblasts. The third involves activation of osteoclasts, and the fourth is the mineralization of osteoid and completion of bone remodelling [7]. Normal bone remodelling is under tight control. However, the net loss of bone occurs in postmenopausal women due to aging and menopause. In addition to the interactions between osteoclasts, osteoblasts, osteocytes, gravity, mechanical stress, and strains of daily living activities, and several systemic hormones regulate bone remodelling. These hormones include estrogens (i.e., estradiol, estrone), androgens (i.e., testosterone), calcium-regulating hormones, including parathyroid, calcitonin and calcitriol, insulin-growth, thyroid hormones, and cortisol.

Estrogens are essential components in producing longitudinal bone growth, bone mass, and bone remodelling [8]. Estrogen inhibits bone resorption via direct action on osteoclasts [9]. Estradiol decreases by $85 \%$ to $90 \%$ in postmenopausal women relative to premenopausal women [10]. Decreasing circulating estrogen results in an acceleration of bone resorption and disrupts the tightly controlled balance in bone remodelling. Also, decreasing estrogen causes decreased intestinal calcium absorption and increased urinary calcium loss, contributing to bone loss [11].

Reduced bone mass caused by osteoporosis leads to micro-architectural changes in bone that result in fractures. One can think of osteoporosis as an equation. One part of the equation is peak bone mass, achieved by age 30, minus bone loss associated with aging and menopause [12]. Each equation is unique to the individual, based primarily on genetic factors. Genetic factors contribute to up to $75 \%$ of peak bone mass [13-15]. Studies demonstrate two hundred to more than five hundred loci associated with bone mineral density (BMD) and fractures [16, 17]. There are also single nucleotide polymorphisms (SNPs) associated with Al-induced bone loss or fractures $[18,19]$.

\section{Risk Factors}

There are several risk factors for developing osteoporosis [20]. Table 1 identifies the most significant risk factors. The most notable non-modifiable risk factor is a parent who has osteoporosis or suffered a non-traumatic fracture. Women with a maternal history of hip fractures are approximately twice as likely to experience hip fractures as women without a family history [21]. Also, it is essential to identify modifiable risk factors to promote bone health and overall health. A decrease in excessive alcohol consumption, smoking cessation, and increased physical activity can lower the overall fracture risk and promote overall health [22]. Secondary causes of osteoporosis further increase bone loss, including aromatase inhibitors (Table 1).

Table 1 Risk Factors for Osteoporosis.

\begin{tabular}{|c|c|c|}
\hline Modifiable Risk Factors & Non-modifiable Risk factors & Secondary causes of osteoporosis \\
\hline $\begin{array}{l}\text { Alcohol consumption (>2-3 } \\
\text { drinks/day) }\end{array}$ & $\begin{array}{l}\text { Parental history of non- } \\
\text { traumatic fracture }\end{array}$ & $\begin{array}{l}\text { Chronic use of certain medications } \\
\text { (steroids) }\end{array}$ \\
\hline Cigarette smoking & non-traumatic & Hyperparathyroidism \\
\hline
\end{tabular}




\begin{tabular}{lll}
$\begin{array}{l}\text { Inadequate nutritional } \\
\text { status }\end{array}$ & Low body mass & Hypogonadism \\
Decreased physical activity & Gender & Rheumatoid Arthritis \\
& Age ( $>50$ years) & $\begin{array}{l}\text { Diabetes, liver disease, chronic } \\
\text { kidney disease, }\end{array}$ \\
& Ethnicity & Aromatase inhibitors \\
\hline
\end{tabular}

*Below age 50 years

\section{Screening for Osteoporosis}

Screening for osteoporosis does not differ in women with and without breast cancer. The most commonly used screening test for osteoporosis is the dual-energy x-ray absorptiometry (DXA) of the lumbar spine, hip, and femoral neck. The DXA provides bone mineral density (BMD) measurements. DXA scans report $T$ and $Z$ scores. The $T$ score is the number of standard deviations (SD) above or below the mean BMD of an average young adult of the same sex between twenty and twenty-nine years of age. According to the World Health Organization, a T score of -1.0 and above is normal bone density. A T-score between -1.0 and -2.5 indicates osteopenia, and a T-score of -2.5 or below or having a fragility fracture is osteoporosis. The fracture risk increases nearly two-fold for every SD below the mean BMD for a young adult $[23,24]$. Figure $3 A$ illustrates the relationship between decreasing T-scores, increasing age, and hip fracture risks.

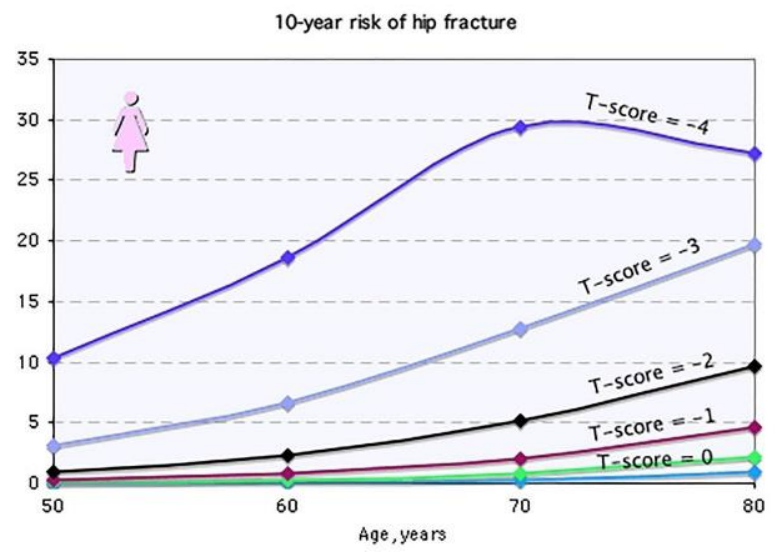

Figure 3 The 10-year Hip Fracture Risk by T-score and Age in the General Population. The fracture risk increases by age and T-score. For example, a 70-year-old with a T-score of -3.0 has a hip fracture risk of about $13 \%$ over the next 5 -years.

A similar relationship exists between decreasing T-scores, increasing age, and the vertebral fracture risks (data not shown). Considering that many vertebral fractures are asymptomatic It is important to perform a dorsal and lumbar spine $\mathrm{x}$-ray in order to see morphometric vertebral fractures. Indications for lumbar plain $\mathrm{x}$-ray if the woman experiences a loss of height greater than $3 \mathrm{~cm}$. An osteoporosis diagnosis should be established if vertebral or non-vertebral fragility has been identified irrespective of the T score. The $Z$ score compares an individual's bone density with that of 
an average person of the same age and sex and helps evaluate osteoporosis's secondary causes. If the Z-score is less than normal a secondary cause of osteoporosis is more likely. Osteoporosis has many secondary causes [25] (see Table 1 for a partial list of most common causes of secondary osteoporosis).

The DXA remains the gold standard for screening for osteoporosis. However, the DXA scan has its limitations. It provides a two-dimensional projection of a three-dimensional structure and does not capture the three-dimensional bone geometry or microarchitecture. Therefore, it does not represent an actual volumetric bone mineral density [26]. Frost outlines seventeen problems on the use DXA scans in his paper "Absorptiometry and "osteoporosis" problems [27]. Additionally, there is a lack of standardization in bone and soft tissue measurements, with discrepancies in measurements obtained on instruments from different DXA manufacturers. It is important to use the same DXA instrument for serial DXA screenings to accurately depict bone density changes over time.

\section{Estimating the Fracture Risk}

In addition to DXA scans, there are additional tools used to assess fracture risk. The Fracture Risk Assessment Tool (FRAX ${ }^{\circledR}$ ) provides an assessment of fractures' prediction in men and women. FRAX ${ }^{\circledR}$ uses specific clinical risk factors with or without femoral neck bone mineral density [28]. These risk factors include age, sex, race, height, weight, body mass index, personal history of an osteoporotic fracture, parental history of hip fracture, use of oral glucocorticoids, rheumatoid arthritis, other secondary causes of osteoporosis, current smoking, and alcohol intake of three or more units daily. The algorithm calculates the ten-year risks of developing a hip or major osteoporotic fracture. Tenyear risk of a hip fracture that exceeds $3 \%$ or a $20 \%$ risk for overall major osteoporotic fractures warrants treatment with anti-resorption medications [29]. A DXA scan should be obtained at the initiation of the medication and then repeated at regular intervals.

Modifications to $\mathrm{FRAX}^{\circledR}$ when assessing Al-induced bone loss include checking "secondary osteoporosis" [30]. This practice is called into question by a Canadian-based registry cohort study. In the registry study, the designation of "secondary osteoporosis" as a risk factor for Al-induced bone loss overestimates fracture risks [31]. In multivariate analysis, women with breast cancerinitiating Al-therapy had a higher body mass index, higher BMD, lower osteoporosis prevalence, and fewer prior fractures than women not starting Als or the healthy population [32]. The implications being Als do not cause as many fractures as previously thought. These two studies are case-control registry studies and, as such, subject to several biases [33].

\section{Calcium and Vitamin D}

Calcium and vitamin D supplementation mitigate bone loss. However, calcium and vitamin D's role in reducing fractures remains controversial. Both calcium and vitamin D plays a significant role in maintaining bone health. Along with phosphorus, calcium is part of the mineral component of bone. While it is stored primarily in bone and teeth, plasma calcium concentrations dictate calcium balance in the body. As plasma calcium decreases, bone resorption increases, impacting the architecture of bone [34, 35]. Vitamin D enhances intestinal absorption of calcium, maintaining serum calcium levels. Decreased concentrations of vitamin $D$ disrupts plasma calcium homeostasis that can result in excessive bone resorption. Also, parathyroid hormone (PTH) plays a role in 
maintaining calcium homeostasis. In the bone, PTH inhibits osteoblast activity and stimulates osteoclast activity leading to bone breakdown and calcium release. In the kidneys, PTH increases calcium reabsorption and blocks phosphate reabsorption from the tubules. Also, PTH acts at the kidneys to stimulate the formation of vitamin $D[36,37]$.

Ingested calcium is absorbed from the intestine passively and by mediated vitamin $D$ active transport. Both mechanisms' efficiency decline with age and supplementation becomes necessary in maintaining bone health [38]. While the recommended dosage of calcium and vitamin D3 supplementation vary, most clinical guidelines recommend 1000-1200 mg of calcium (including dietary and supplemental) and 800-1000 IU of Vitamin D3 per day for women over the age of 50 [39]. Recommendations for postmenopausal women on Als are similar, but studies remain limited in this area [40]. Vitamin D3 insufficiency (less than $30 \mathrm{ng} / \mathrm{ml}$ ) or deficiency (less than $20 \mathrm{ng} / \mathrm{ml}$ ) is common in the general population [41], and women with breast cancer [42], especially in minority populations [42]. Assess vitamin D3 levels either before starting Als or when the baseline DXA shows osteopenia or osteoporosis.

A recent systematic review examined the evidence that calcium supplementation reduces the risk of fractures. The conclusions were that dietary calcium intake is not associated with a reduced risk of fractures [43]. Another systematic review and meta-analysis included 33 randomized clinical trials and over 51,100 individuals. The use of supplements that included calcium, vitamin $D$, or both was not associated with a significant difference in hip fracture risk than placebo or no treatment control in community-dwelling older adults [44].

\section{Aromatase inhibitor-induced Bone Loss}

Hormone receptor-positive breast cancers represent nearly seventy-five percent of all breast cancers. The Als anastrozole, exemestane, and letrozole are the preferred treatment for postmenopausal women with hormone receptor-positive breast cancer [45]. The majority of postmenopausal women will be treated with an Al for five or ten years to reduce breast cancer recurrence risk and improve overall survival [46]. Als work by inhibiting the P450 cytochrome CYP19 or aromatase, responsible for converting androgens to estrogens $[47,48]$. Aromatase is in tissues throughout the body, including breast, bone, brain, and ovary. Als specifically inhibit aromatase that converts androgens to estrogens [49]. As Als serve to reduce estrogen levels, this accelerates bone loss that will lead to osteoporosis and fractures in some women $[2,40]$.

Table 2 describes the risks of fractures with Als or tamoxifen in the major trials in postmenopausal women [45, 50-53]. The Al-related fracture risk remains elevated during the treatment period of five years. During years five to ten, fracture rates decrease to those of tamoxifen. Als also cause an increase in bone turn over markers which correlates loss of BMD, osteoporosis, and fractures [54]. However, the bone turnover markers are not, as yet, used for clinical decision making.

Table 2 Fractures Rates in Randomized Trials of Aromatase Inhibitors versus Tamoxifen.

\begin{tabular}{lllllll}
\hline Trial. & N & Follow-up (mo.) & Treatment & $\begin{array}{l}\text { Fractures } \\
(\%)\end{array}$ & $\boldsymbol{p}$-value & Ref \\
\hline $\begin{array}{l}\text { Al vs. Tam } \\
\text { ATAC }\end{array}$ & 9336 & 100 & ANA vs. TAM & 11 vs. 7.7 & $<0.001$ & {$[45]$} \\
\hline
\end{tabular}




\begin{tabular}{lcccccc}
\hline BIG 1-98 & 4922 & 60 & LET vs. TAM & 9.3 vs. 6.5 & 0.002 & [50] \\
$\begin{array}{l}\text { Al after 2-3 yrs. of TAM } \\
\text { TEAM }\end{array}$ & 9779 & 61 & EXE vs. TAM & 5.0 vs. 3.0 & 0.0001 & {$[51]$} \\
ABCSG8/ARNO & 3224 & 28 & ANA vs. TAM & 2.0 vs. 1.0 & 0.015 & {$[52]$} \\
$\begin{array}{l}\text { Al after 5 yrs. of TAM } \\
\text { MA-17 }\end{array}$ & 5187 & 63 & & & & \\
\hline
\end{tabular}

Abbreviations: Anastrozole (ANA); Exemestane (EXE); Letrozole (LET); Tamoxifen (TAM).

Figure 4 suggests an approach to Al-induced bone loss (modified from references [40] and [30]). It starts with risk factor assessment, addressing modifiable risk factors (i.e., reducing alcohol consumption, smoking cessation, encouraging physical activity and weight-bearing exercise), and consuming about $1200 \mathrm{mg}$ of calcium (between dietary sources and supplements) and 800-1000 IU per day of vitamin D3. Obtain a baseline DXA scan and repeat regular intervals (e.g., every two years) and, depending on T-scores, institute anti-resorption drugs to prevent or treat osteoporosis (Figure 4).

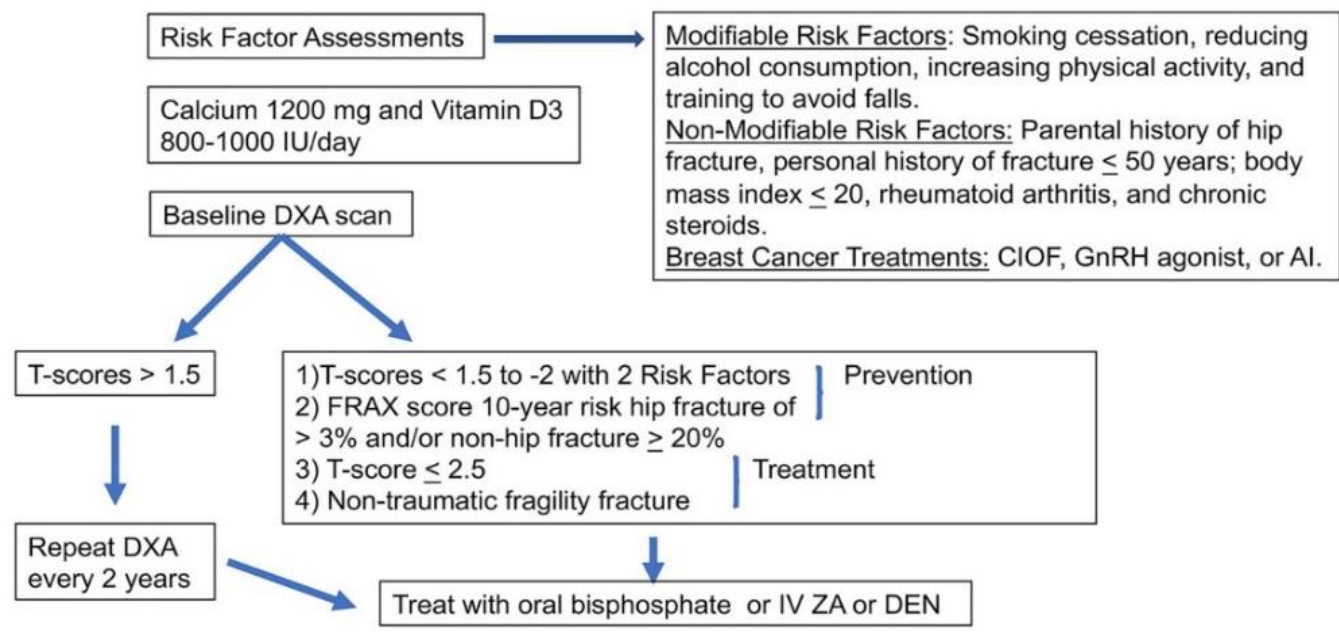

Abbreviations: Dual energy absorptiometry (DXA); chemotherapy-induced ovarian failure (CIOF); gonadotrophin-releasing hormone (GnRH); aromatase inhibitor (Al); zoledronic acid (ZA); denosumab (DEN)

Figure 4 Algorithm for Bone Heath in Women with Breast Cancer. Assessment of fracture risk starts with dividing the risk factor assessment into modifiable and non-modifiable risks. Every woman should take 800-1000 IU/day of vitamin D3 and Calcium 1200 $\mathrm{mg} /$ day (made up of dietary sources and supplemental calcium). Vitamin D3 deficiency $(20 \mathrm{ng} / \mathrm{ml}$ or less) or insufficiency $(30 \mathrm{ng} / \mathrm{ml})$ is common in the general population and breast cancer survivors and should be corrected. Obtain a DXA scan; if T-score is -1.5 or greater in the femoral neck, repeat DXA every two years. Institute treatment with an oral bisphosphonate, ZA or DEN if the T-score is less than -1.5 with two or more risk factors (i.e., receiving treatment with an $\mathrm{Al}$, age over 65 years, family history of hip fracture, body mass index of less than 20, fragility fracture at age less than 50 years, or current smoking). If the $F R A X{ }^{\circledR}$ score shows that, major osteoporotic fracture risk is $20 \%$ or more, or the hip fracture risk is $3 \%$ or more institute drug therapy. (Algorithm modified from references [40] and [30]). 


\section{Drug Treatments for Osteoporosis}

The drugs for osteoporosis treatment include oral and intravenous (iv) bisphosphonates and the RANKL inhibitor denosumab (DEN). Table 3 describes ZA and DEN [55-58]. The differences between ZA and DEN are their mechanisms of action, pharmacokinetics, administration, and costs. Table 4 describes the major trials of Al-induced bone loss [59-64]. Most of these trials rely on bone mineral density (BMD) as a surrogate for fractures. The one exception of the Austrian Breast Cancer Study Group (ABCSG) trial 18 [62]. ABCSG trial 18 was a double-blind placebo-controlled trial of DEN in over 3400 postmenopausal women receiving Als. With six years of median follow-up, there was a $50 \%$ reduction in fractures (hazard rate $(\mathrm{HR})=0.50$ (95\% $\mathrm{Cl} 0.39-0.65)$. In the randomized controlled AZURE trial with a median follow-up of 7 years, there were $6.2 \%$ fractures in the iv ZA group and 8.3\% fractures in the control group (hazard ratio (HR) $0.6995 \% \mathrm{Cl} 0.53$ to $0.90, p=0.005$ ) [65].

Table 3 Comparison of ZA and Den.

\begin{tabular}{|c|c|c|}
\hline Factor & ZA (iv) & $\operatorname{DEN}(\mathrm{sc})$ \\
\hline Dose & $4^{@}$ or $5 \mathrm{mg}^{\dagger}$ & $60^{@}$ or 120 mg@u \\
\hline Mechanism & Osteoclast inhibitor & RANKL monoclonal antibody \\
\hline Metabolism & Not Metabolized & Not Metabolized \\
\hline Half-life & 2.5 hrs., ${ }^{*} 188$ days $^{*}$ & 28 days \\
\hline Clearance & Renal & RES \\
\hline Schedule & Every 6 months & Every 6 months \\
\hline Common side effects & $\begin{array}{l}\text { Fever, chills; muscle, bone or joint } \\
\text { pain; nausea; fatigue; headaches }\end{array}$ & Joint, muscle pains; hypocalcaemia \\
\hline Rare side effects & $\begin{array}{l}\text { Osteonecrosis }{ }^{\natural} \text {; renal insufficiency } \\
\text { atypical femur fractures }[66]^{\natural}\end{array}$ & $\begin{array}{l}\text { Osteonecrosis"; rebound vertebral } \\
\text { fractures [67], and atypical femur } \\
\text { fractures [68]" }\end{array}$ \\
\hline & $\begin{array}{l}\text { For creatine clearance }<60 \mathrm{ml} / \mathrm{min} \\
\text { modify ZA as follows: } \\
50-60 \mathrm{~min} / \mathrm{ml}=3.5 \mathrm{mg}\end{array}$ & \\
\hline Dose modifications & $\begin{array}{l}40-49 \mathrm{~min} / \mathrm{ml}=3.3 \mathrm{mg} \\
30-39 \mathrm{~min} / \mathrm{ml}=3.0 \mathrm{mg} \\
\text { Do not give ZA when the creatinine } \\
\text { clearance }<30 \mathrm{ml} / \mathrm{min}\end{array}$ & None \\
\hline Costs $^{\&}$ (US dollars) & 252.00 & 1906.00 \\
\hline
\end{tabular}

Abbreviations: zoledronic acid (ZA); intravenous (iv); denosumab (DEN); subcutaneous (sc); reticuloendothelial system (RES)

@Once every 6 months

${ }^{\dagger}$ One dose annually approved non-cancer-related osteoporosis

${ }^{\mu}$ The dose for skeletal metastases

"The half-life in the blood; ${ }^{*}$ Most goes to bone

${ }^{\S}$ Dose-dependent and rate of infusion dependent

"The incidence atypical femur fractures and osteonecrosis is well less than one percent.

${ }^{\&}$ Costs of drug and administration from the Centers for Medicare and Medicaid Services

Reimbursement (www.cms.gov) 
Table 4 Major Trials of Anti-Resorptive Drugs in Aromatase inhibitor-induced Bone Loss.

\begin{tabular}{|c|c|c|c|c|c|}
\hline Trial & Treatments & $n$ & $\begin{array}{l}\text { Results } \\
{\text { (L/S BMD })^{+}}\end{array}$ & $p$-value & Ref \\
\hline Brufsky & $\begin{array}{l}\text { ZA } 4 \text { mg iv q6 mo for } 1 \text { yr vs. } \\
\text { delayed }\end{array}$ & 502 & 2.0 vs. -2.5 & $<0.001$ & [59] \\
\hline Coleman & $\begin{array}{l}\text { ZA } 4 \text { mg iv q6 mo for } 5 \text { yrs vs. } \\
\text { delayed }\end{array}$ & 1065 & 4.3 vs. -5.4 & $<0.0001$ & [60] \\
\hline Ellis & $\begin{array}{l}\text { DEN } 60 \text { mg sc q6 mo for } 2 \text { years vs. } \\
\text { placebo }\end{array}$ & 262 & 6.0 vs. -1.6 & $<0.0001$ & [61] \\
\hline Gnant & $\begin{array}{l}\text { DEN } 60 \text { mg sc q6 mo for } 5 \text { years vs. } \\
\text { placebo }\end{array}$ & 3425 & $\begin{array}{l}\mathrm{HR} \text { fractures }=0.5095 \% \\
\mathrm{Cl} 0.39-0.65\end{array}$ & $<0.0001$ & [62] \\
\hline $\begin{array}{l}\text { Van } \\
\text { Poznak }\end{array}$ & $\begin{array}{l}\text { Risedronate oral } 35 \mathrm{mg} / \text { week for } 2 \\
\text { years vs. placebo }\end{array}$ & 111 & 2.2 vs. -1.85 & $<0.0001$ & [63] \\
\hline Sestak & $\begin{array}{l}\text { Risedronate oral } 35 \mathrm{mg} / \text { week for } 3 \\
\text { years vs. placebo }\end{array}$ & 150 & 1.1 vs. -2.6 & $<0.0001$ & [64] \\
\hline
\end{tabular}

Abbreviations: Zoledronic acid (ZA); denosumab (DEN); hazard ratio (HR); †percentage change in the lumbar spine per year.

\subsection{Oral and IV Bisphosphonates}

Figure 5 illustrates the nitrogen-containing bisphosphonates. Bisphosphonates have a high affinity for bone mineral matrix because they bind to hydroxyapatite crystals. When osteoclasts resorb bone, bisphosphonate is released and impairs the osteoclast's ability to complete bone resorption [69, 70]. Oral and iv bisphosphonates have a nitrogen-containing R2 side chain, promoting osteoclast apoptosis by interfering with intracellular signalling of critical regulatory proteins [71, 72]. 


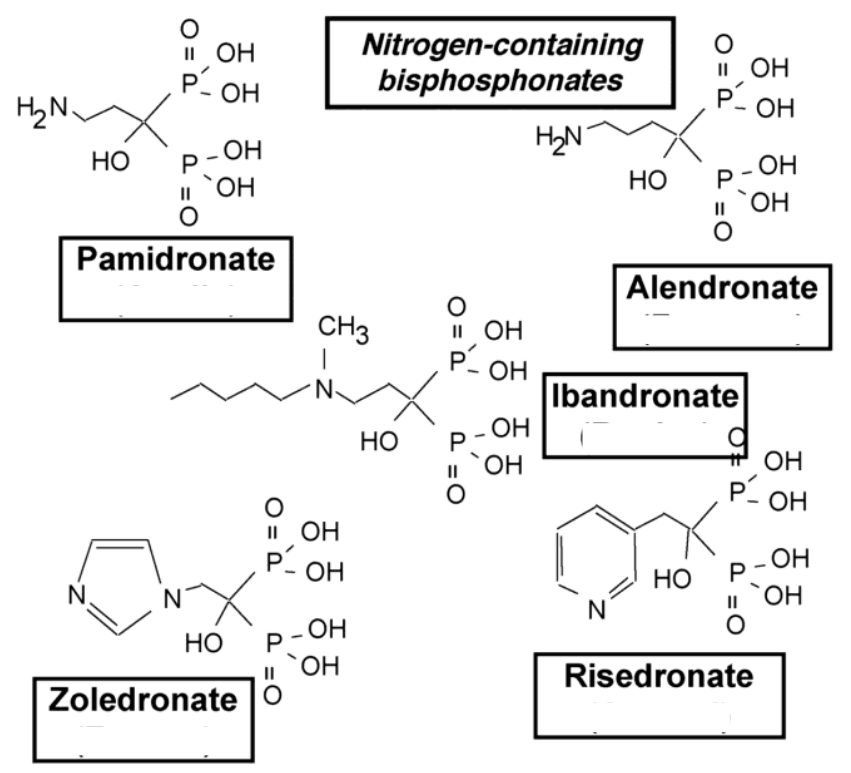

Figure 5 Structures of the $\mathbf{N}$-amino Bisphosphonates. These drugs are analogs of inorganic pyrophosphate, a significant constituent of the bone mineral matrix. When osteoclasts take up the bone mineral matrix, the n-amino bisphosphonates inhibit farnesyl diphosphate synthase, responsible for converting dimethylallyl diphosphate to farnesyl diphosphate (FDP). Thus, leading to the inhibition of the post-translational modifications (or isoprenylation) of guanosine triphosphate (GTP)-binding proteins Rab, Rac, and Rho. These GTP binding proteins are critical for osteoclast resorption of bone.

Oral bisphosphonates, alendronate, risedronate, and ibandronate, are more commonly prescribed than iv bisphosphonates, but they are associated with low bioavailability, compliance considerations, and adverse drug reactions, including GI-related toxicities. ZA is the most potent iv bisphosphonate and can be given every six months or once yearly. ZA's side effects include an acutephase reaction including myalgias and arthralgias, low-grade fever, and bone pain that often resolves within twenty-four to seventy-two hours post-infusion. Also, it causes renal insufficiency, and rarely atypical femur fractures and osteonecrosis of jaw [73].

Bisphosphonate dosing is calculated based on the estimated creatinine clearance rate (https://www.accessdata.fda.gov/drugsatfda docs/label/2014/021223s028lbl.pdf). Avoid bisphosphonates in glomerular filtration rates of less than $30-35 \mathrm{~mL} / \mathrm{min}[74,75]$. Both oral bisphosphonates, ZA, and DEN, are associated with the severe side effect of osteonecrosis of the jaw that is dose and duration-dependent. Dental screenings should occur before initiating therapy [76]. With osteoporosis treatment every six months, both DEN [77] and ZA [78] have a zero incidence of osteonecrosis. In non-clinical trial settings, the incidence may be slightly higher than zero. The risks of both drugs are rare, and the benefit-to-risk ratio favors treatment with antiresorptive drugs.

\subsection{Denosumab}

DEN is a human form of a monoclonal to RANKL, thereby slowing bone resorption (Figure 2) [79, 80]. The FREEDOM trial (Fracture Reduction Evaluation of Denosumab in Osteoporosis every 
Six Months) was a phase III, randomized, placebo-controlled clinical trial that compared denosumab $60 \mathrm{mg}$ subcutaneously (SC) every six months and placebo in 7868 postmenopausal women with osteoporosis [81]. The primary efficacy endpoint was new vertebral fractures at 36 months. The denosumab group had statistically significant relative risk reductions for vertebral fractures ( $H R=0.3295 \% \mathrm{Cl} 0.26-0.41, p, 0.001)$, hip fractures ( $H R=0.4095 \% \mathrm{Cl} 0.37-0.97, p=0.04)$, and nonvertebral fractures ( $\mathrm{HR}=0.8095 \% \mathrm{Cl} 0.67-0.95, \mathrm{p}=0.01$ ) compared with placebo. $\mathrm{DEN}$ is typically welltolerated, administered every six months. The side effect profile includes the risk of rebound vertebral fractures after stopping DEN [82], asymptomatic hypocalcaemia, atypical femur fractures [68], and osteonecrosis of the jaw, similar to that of bisphosphonates [83]. In fact, the incidence atypical femur fractures and osteonecrosis of the jaw is well less than one precent with denosumab, zoledronic acid, and oral bisphosphonates.

\section{Drug Choice}

When deciding to prescribe anti-resorptive drugs, a comparative efficacy analysis shows that oral and iv bisphosphonates and DEN reduce fractures [84]. One is not superior to the other [84-86]. Limited head-to-head studies are comparing the effectiveness of ZA versus DEN in treating osteoporosis. In a large population-based cohort study, the risk of osteoporotic fracture was similar between $\mathrm{ZA}$ and $\mathrm{DEN}(\mathrm{HR}=1.2195 \% \mathrm{Cl}, 0.84$ to 1.73). The two drugs have comparable clinical safety and effectiveness after one year of initiation [87]. In women with a history of breast cancer, the selection between oral bisphosphonates, ZA, or DEN depends upon patient and provider preference, specific toxicities (i.e., baseline renal toxicities), compliance considerations, and costs.

The American Society for Bone and Mineral Research formulated guidelines on the optimal duration of bisphosphonate therapy for postmenopausal women with osteoporosis [88]. The guidelines stratify women as low risk versus high risk for fracture. They advise assessing the risk of fracture at five years on oral BPs and three years on IV BPs. Those who are considered high-risk should continue to take oral BPs for up to 10 years or IV therapy for up to six years. Fracture risk should be reassessed every two years during extended therapy.

Postmenopausal women on Al therapy are at an increased risk for fracture and should be monitored closely for fracture risk through treatment duration. The European Society for Clinical and Economic Aspects of Osteoporosis, Osteoarthritis, and Musculoskeletal Diseases recommends ZA, or DEN, be administered every six months for the entire Al treatment period for all osteoporotic women [89]. However, the authors disagree with this recommendation preferring to use the algorithm outlined in Figure 4. In the ZO-Fast trial results [60], only twenty-seven percent of the "delayed group" (the randomized ZA group only when the T-score was less than -2.0, or a fragility fracture occurred) received ZA during the first five years of the trial. That means eighty-three percent of women were over treated with ZA during the first five years of follow-up on the ZO-fast.

\section{Anti-Cancer Effects of Anti-Resorptive Drugs}

Anti-cancer effects of bisphosphonates and denosumab were observed in preclinical models [90, 91]. Disseminated tumor cells (DTCs) reside in the bone marrow and contribute to other sites of metastases [92]. DTCs serve as a prognostic factor in early breast cancer [93], and ZA can reduce DTCs in the human bone marrow $[94,95]$. These observations led to the hypothesis that anti- 
osteoporotic drugs not only mitigate bone loss and reduce fractures but have anti-cancer effects as well. This hypothesis was tested in the clinic.

Several randomized trials [62, 78, 96, 97] and meta-analysis restricted to bisphosphonates [98] show statistically significant reductions in distant metastases, skeletal metastases, and cancer mortality but are only observed in postmenopausal women. The Early Breast Cancer Trialists' Collaborative Group included over 6000 premenopausal and over 11,000 postmenopausal women. Whereas there was no effect in premenopausal women, there was an absolute reduction in bone metastases $(2.2 \% p=0.0002)$ and cancer mortality $(3.3 \% p=0.002)$ in postmenopausal women. In 2017 the Joint Canadian Care Ontario and American Society of Clinical Oncology Practice Guideline put out a statement saying that "consider" ZA (4 mg iv) every six months for three to five years, or oral clodronate ( 1600 orally/day, not available in the US) for three years in high-risk postmenopausal women [99]. Additional trials in postmenopausal women are needed to confirm the results of the meta-analysis [100].

Fifty-three percent of consensus participants said "yes," but $37 \%$ of them said "no" to the use of adjuvant ZA with ovarian suppression and Al or tamoxifen at St. Gallen/Vienna Consensus Discussion [101]. However, when queried about the use of adjuvant ZA, only $43 \%$ of consensus participants said "yes." Finally, the European Society of Medical Oncology recommends adjuvant bisphosphonates for those who undergo ovarian suppression or are postmenopausal, especially if they are at a high risk of relapse [102]. Thus, there is still considerable uncertainty about the use of adjuvant $Z A$.

Two other trials of denosumab are published. The randomized, placebo-controlled D-CARE of adjuvant denosumab vs. placebo [103], and Austrian Breast Cancer Study Group (ABCSG) trial 18 was another randomized placebo-controlled trial whose primary endpoint was fractures [62]. In DCARE ( $n=4509)$, the denosumab schedule was intensive with sc every three to four weeks for the first six months, then every three months for five years. The D-CARE trial was wholly negative, even postmenopausal women. That is there were no reductions cancer mortality and bone metastases for the denosumab versus placebo-treated women.

ABCSG ( $n=3425)$ with six years of median follow-up, the disease-free survival (DFS) was statistically significantly higher in favor of the denosumab treatment (hazard ratio $(\mathrm{HR})=0.8295 \% \mathrm{Cl}$ 0.69 to $0.98, p=0.026$ ) [77]. However, when one looks at hard endpoints (e.g., invasive local-regional and distant recurrences, invasive contralateral breast cancers, and deaths), there were no differences between denosumab and placebo. Contributing to "statistical significance" was nonhistologically verified distant metastases and second breast cancers and non-breast invasive cancers.

Southwest Oncology Group (SWOG) trial of zoledronic acid vs. oral clodronate or ibandronate [104]. In the SWOG trial (n-6097), ZA's schedule was intensive with monthly iv for six months and every three months for three years, and doses of clodronate and ibandronate were 1600 and 50 $\mathrm{mg} /$ day, respectively. SWOG was a negative trial even divided by age (less or equal or greater than 55 years of age. Only about $40 \%$ of medical oncologists routinely use bisphosphonates in their "high risk" postmenopausal women [101], reflecting the literature's uncertainty and limitations.

A newer drug approved by the Food and Drug Administration for postmenopausal osteoporosis treatment is the monoclonal antibody romosozumab $[105,106]$. Romosozumab binds sclerostin, produced by osteocytes, and increases new bone formation, and reduces fractures. A randomized, double-blind phase III comparing monthly sc romosozumab and weekly oral alendronate in over four thousand osteoporotic women showed a $48 \%$ reduction in vertebral fractures $(\mathrm{HR}=0.5295 \% \mathrm{Cl}$ 
0.61-0.66, $p<0.001$ ) with acceptable side-effects [105]. Romosozumab requires testing in breast cancer survivors for osteoporosis and in the metastatic setting. Also, newer RANKL inhibitors are in development [107].

\section{Conclusions}

Osteoporosis remains a growing concern worldwide, with approximately nine million osteoporotic-related fractures occurring every year [108]. It continues to be a prominent public health concern, particularly in the elderly. Postmenopausal women with a history of breast cancer on Als are at an increased risk of developing osteoporosis and subsequent fragility fractures. Some of these fractures are preventable. Despite assessment tools and treatment guidelines, compliance with guidelines is not optimal [109]. The algorithm outlined in Figure 4 is a suggested approach for Al-induced bone loss. The choice between oral, IV bisphosphonates, or DEN, as all these drugs increase BMD and reduce fractures, depends on patient and provider, specific toxicities (e.g., renal toxicity), compliance, and cost considerations. Women with breast cancer should identify the provider (e.g., the primary care provider or specialty physician) depending on local expertise and practice patterns responsible for bone health.

\section{Author Contributions}

$\mathrm{J}$ Lamond participated in literature review, was responsible for the first draft, made comments on multiple drafts, and reviewed the final manuscript. CL Shapiro conceptualized the review, formulated the outline for the literature review, edited the first draft, responded to comments of the reviewers for the first and subsequent drafts, and reviewed the final manuscript.

\section{Competing Interests}

The authors declare no conflicts of interest.

\section{References}

1. Gnant M, Mlineritsch B, Luschin-Ebengreuth G, Kainberger F, Kassmann H, Piswanger-Solkner $\mathrm{JC}$, et al. Adjuvant endocrine therapy plus zoledronic acid in premenopausal women with earlystage breast cancer: 5-year follow-up of the ABCSG-12 bone-mineral density substudy. Lancet Oncol. 2008; 9: 840-849.

2. Hadji P. Aromatase inhibitor-associated bone loss in breast cancer patients is distinct from postmenopausal osteoporosis. Crit Rev Oncol Hematol. 2009; 69: 73-82.

3. Lupsa BC, Insogna K. Bone health and osteoporosis. Endocrinol Metab Clin North Am. 2015; 44: 517-530.

4. Creecy A, Damrath JG, Wallace JM. Control of bone matrix properties by osteocytes. Front Endocrinol (Lausanne). 2020; 11: 578477.

5. Kitaura H, Marahleh A, Ohori F, Noguchi T, Shen WR, Qi JW, et al. Osteocyte-related cytokines regulate osteoclast formation and bone resorption. Int J Mol Sci. 2020; 21: 5169.

6. Tresguerres FG, Torres J, Lopez-Quiles J, Hernandez G, Vega JA, Tresguerres IF. The osteocyte: A multifunctional cell within the bone. Ann Anat. 2020; 227: 151422.

7. Feng X, McDonald JM. Disorders of bone remodeling. Annu Rev Pathol. 2011; 6: 121-145. 
8. Gennari L, Merlotti D, Nuti R. Aromatase activity and bone loss. Adv Clin Chem. 2011; 54: 129164.

9. Kameda T, Mano H, Yuasa T, Mori Y, Miyazawa K, Shiokawa M, et al. Estrogen inhibits bone resorption by directly inducing apoptosis of the bone-resorbing osteoclasts. J Exp Med. 1997; 186: 489-495.

10. Khosla S, Atkinson EJ, Melton $\amalg$, Riggs BL. Effects of age and estrogen status on serum parathyroid hormone levels and biochemical markers of bone turnover in women: A population-based study. J Clin Endocrinol Metab. 1997; 82: 1522-1527.

11. Armas LA, Recker RR. Pathophysiology of osteoporosis: New mechanistic insights. Endocrinol Metab Clin North Am. 2012; 41: 475-486.

12. Ramaswamy B, Shapiro CL. Osteopenia and osteoporosis in women with breast cancer. Semin Oncol. 2003; 30: 763-775.

13. Ralston SH, Uitterlinden AG. Genetics of osteoporosis. Endocr Rev. 2010; 31: 629-662.

14. Zhu XZ, Wang ZY, Zhao YX, Jiang C. Investigation of candidate genes and mechanisms underlying postmenopausal osteoporosis using bioinformatics analysis. Mol Med Rep. 2018; 17: 15611572.

15. Al-Barghouthi BM, Farber CR. Dissecting the genetics of osteoporosis using systems approaches. Trends Genet. 2019; 35: 55-67.

16. Hsu YH, Estrada K, Evangelou E, Ackert-Bicknell C, Akesson K, Beck T, et al. Meta-analysis of genomewide association studies reveals genetic variants for hip bone geometry. J Bone Miner Res. 2019; 34: 1284-1296.

17. Morris JA, Kemp JP, Youlten SE, Laurent L, Logan JG, Chai RC, et al. An atlas of genetic influences on osteoporosis in humans and mice. Nat Genet. 2019; 51: 258-266.

18. Liu M, Goss PE, Ingle JN, Kubo M, Furukawa $Y$, Batzler A, et al. Aromatase inhibitor-associated bone fractures: A case-cohort GWAS and functional genomics. Mol Endocrinol. 2014; 28: 17401751.

19. Artigalas O, Vanni T, Hutz MH, Ashton-Prolla P, Schwartz IV. Influence of CYP19A1 polymorphisms on the treatment of breast cancer with aromatase inhibitors: A systematic review and meta-analysis. BMC Med. 2015; 13: 1-10.

20. Pouresmaeili F, Kamalidehghan B, Kamarehei M, Goh YM. A comprehensive overview on osteoporosis and its risk factors. Ther Clin Risk Manag. 2018; 14: 2029-2049.

21. Dawson-Hughes B, Looker AC, Tosteson AN, Johansson H, Kanis JA, Melton $\amalg$. The potential impact of new national osteoporosis foundation guidance on treatment patterns. Osteoporos Int. 2010; 21: 41-52.

22. Camacho PM, Dayal AS, Diaz JL, Nabhan FA, Agarwal M, Norton JG, et al. Prevalence of secondary causes of bone loss among breast cancer patients with osteopenia and osteoporosis. J Clin Oncol. 2008; 26: 5380-5385.

23. Cummings SR, Bates D, Black DM. Clinical use of bone densitometry: Scientific review. JAMA. 2002; 288: 1889-1897.

24. Marshall $D$, Johnell $O$, Wedel $H$. Meta-analysis of how well measures of bone mineral density predict occurrence of osteoporotic fractures. BMJ. 1996; 312: 1254-1259.

25. Mirza F, Canalis E. Management of endocrine disease: Secondary osteoporosis: Pathophysiology and management. Eur J Endocrinol. 2015; 173: R131-R151. 
26. Unnanuntana A, Gladnick BP, Donnelly E, Lane JM. The assessment of fracture risk. J Bone Joint Surg Am. 2010; 92: 743-753.

27. Frost HM. Absorptiometry and "osteoporosis": Problems. J Bone Miner Metab. 2003; 21: 255260.

28. Kanis JA, McCloskey EV, Johansson H, Oden A, Strom O, Borgstrom F. Development and use of FRAX in osteoporosis. Osteoporos Int. 2010; 21: S407-S413.

29. Kanis JA, Harvey NC, Johansson $H$, Liu E, Vandenput L, Lorentzon $M$, et al. A decade of FRAX: How has it changed the management of osteoporosis? Aging Clin Exp Res. 2020; 32: 187-196.

30. Shapiro CL, Van Poznak C, Lacchetti C, Kirshner J, Eastell R, Gagel R, et al. Management of osteoporosis in survivors of adult cancers with nonmetastatic disease: ASCO clinical practice guideline. J Clin Oncol. 2019; 37: 2916-2946.

31. Leslie WD, Morin SN, Lix LM, Niraula S, McCloskey EV, Johansson H, et al. Performance of FRAX in women with breast cancer initiating aromatase inhibitor therapy: A registry-based cohort study. J Bone Miner Res. 2019; 34: 1428-1435.

32. Leslie WD, Morin SN, Lix LM, Niraula S, McCloskey EV, Johansson H, et al. Fracture risk in women with breast cancer initiating aromatase inhibitor therapy: A registry-based cohort study. Oncologist. 2019; 24: 1432-1438.

33. Shapiro CL, Recht A. Side effects of adjuvant treatment of breast cancer. N Engl J Med. 2001; 344: 1997-2008.

34. Reid IR, Bolland MJ. Calcium and/or vitamin D supplementation for the prevention of fragility fractures: Who needs it? Nutrients. 2020; 12: 1011.

35. Sunyecz JA. The use of calcium and vitamin $D$ in the management of osteoporosis. Ther Clin Risk Manag. 2008; 4: 827-836.

36. Veldurthy V, Wei R, Oz L, Dhawan $\mathrm{P}$, Jeon YH, Christakos S. Vitamin D, calcium homeostasis and aging. Bone Res. 2016; 4: 1-7.

37. Bienaime F, Prie D, Friedlander G, Souberbielle JC. Vitamin D metabolism and activity in the parathyroid gland. Mol Cell Endocrinol. 2011; 347: 30-41.

38. Heaney RP, Gallagher JC, Johnston CC, Neer R, Parfitt AM, Whedon GD. Calcium nutrition and bone health in the elderly. Am J Clin Nutr. 1982; 36: 986-1013.

39. Kling JM, Clarke BL, Sandhu NP. Osteoporosis prevention, screening, and treatment: A review. J Womens Health. 2014; 23: 563-572.

40. Hadji P, Aapro MS, Body JJ, Gnant M, Brandi ML, Reginster JY, et al. Management of Aromatase Inhibitor-Associated Bone Loss (AIBL) in postmenopausal women with hormone sensitive breast cancer: Joint position statement of the IOF, CABS, ECTS, IEG, ESCEO IMS, and SIOG. J Bone Oncol. 2017; 7: 1-12.

41. Gallagher JC, Sai AJ. Vitamin D insufficiency, deficiency, and bone health. J Clin Endocrinol Metab. 2010; 95: 2630-2633.

42. Nogues X, Servitja S, Pena MJ, Prieto-Alhambra D, Nadal R, Mellibovsky L, et al. Vitamin D deficiency and bone mineral density in postmenopausal women receiving aromatase inhibitors for early breast cancer. Maturitas. 2010; 66: 291-297.

43. Bolland MJ, Leung W, Tai V, Bastin S, Gamble GD, Grey A, et al. Calcium intake and risk of fracture: Systematic review. BMJ. 2015; 351: h4580. 
44. Zhao JG, Zeng XT, Wang J, Liu L. Association between calcium or vitamin D supplementation and fracture incidence in community-dwelling older adults: A systematic review and meta-analysis. JAMA. 2017; 318: 2466-2482.

45. Howell A, Cuzick J, Baum M, Buzdar A, Dowsett M, Forbes JF, et al. Results of the ATAC (Arimidex, Tamoxifen, Alone or in Combination) trial after completion of 5 years' adjuvant treatment for breast cancer. Lancet. 2005; 365: 60-62.

46. Early Breast Cancer Trialists' Collaborative Group. Aromatase inhibitors versus tamoxifen in early breast cancer: Patient-level meta-analysis of the randomised trials. Lancet. 2015; 386: 1341-1352.

47. Pant S, Shapiro CL. Aromatase inhibitor-associated bone loss: Clinical considerations. Drugs. 2008; 68: 2591-2600.

48. Simpson ER, Davis SR. Minireview: Aromatase and the regulation of estrogen biosynthesis-some new perspectives. Endocrinology. 2001; 142: 4589-4594.

49. Fabian CJ. The what, why and how of aromatase inhibitors: Hormonal agents for treatment and prevention of breast cancer. Int J Clin Pract. 2007; 61: 2051-2063.

50. Rabaglio M, Sun Z, Price KN, Castiglione-Gertsch M, Hawle H, Thurlimann B, et al. Bone fractures among postmenopausal patients with endocrine-responsive early breast cancer treated with 5 years of letrozole or tamoxifen in the BIG 1-98 trial. Ann Oncol. 2009; 20: 1489-1498.

51. van de Velde $C J$, Rea D, Seynaeve $C$, Putter $H$, Hasenburg A, Vannetzel JM, et al. Adjuvant tamoxifen and exemestane in early breast cancer (TEAM): A randomised phase 3 trial. Lancet. 2011; 377: 321-331.

52. Jakesz R, Jonat W, Gnant M, Mittlboeck M, Greil R, Tausch C, et al. Switching of postmenopausal women with endocrine-responsive early breast cancer to anastrozole after 2 years' adjuvant tamoxifen: Combined results of ABCSG trial 8 and ARNO 95 trial. Lancet. 2005; 366: 455-462.

53. Goss PE, Ingle JN, Martino S, Robert NJ, Muss HB, Piccart MJ, et al. Randomized trial of letrozole following tamoxifen as extended adjuvant therapy in receptor-positive breast cancer: Updated findings from NCIC CTG MA.17. J Natl Cancer Inst. 2005; 97: 1262-1271.

54. Yao S, Laurent CA, Roh JM, Lo J, Tang L, Hahn T, et al. Serum bone markers and risk of osteoporosis and fragility fractures in women who received endocrine therapy for breast cancer: A prospective study. Breast Cancer Res Treat. 2020; 180: 187-195.

55. Dionisio MR, Mansinho A, Abreu C, Cavaco-Silva J, Casimiro S, Costa L. Clinical and translational pharmacology of drugs for the prevention and treatment of bone metastases and cancerinduced bone loss. Br J Clin Pharmacol. 2019; 85: 1114-1124.

56. Deeks ED. Denosumab: A review in postmenopausal osteoporosis. Drugs Aging. 2018; 35: 163173.

57. Heeke A, Nunes MR, Lynce F. Bone-modifying agents in early-stage and advanced breast cancer. Curr Breast Cancer Rep. 2018; 10: 241-250.

58. Cremers S, Ebetino FH, Phipps R. On the pharmacological evaluation of bisphosphonates in humans. Bone. 2020; 139: 115501.

59. Brufsky A, Harker WG, Beck JT, Carroll R, Tan-Chiu E, Seidler C, et al. Zoledronic acid inhibits adjuvant letrozole-induced bone loss in postmenopausal women with early breast cancer. $\mathrm{J}$ Clin Oncol. 2007; 25: 829-836. 
60. Coleman R, de Boer R, Eidtmann H, Llombart A, Davidson N, Neven P, et al. Zoledronic acid (zoledronate) for postmenopausal women with early breast cancer receiving adjuvant letrozole (ZO-FAST study): Final 60-month results. Ann Oncol. 2013; 24: 398-405.

61. Ellis GK, Bone HG, Chlebowski R, Paul D, Spadafora S, Smith J, et al. Randomized trial of denosumab in patients receiving adjuvant aromatase inhibitors for nonmetastatic breast cancer. J Clin Oncol. 2008; 26: 4875-4882.

62. Gnant M, Pfeiler G, Dubsky PC, Hubalek M, Greil R, Jakesz R, et al. Adjuvant denosumab in breast cancer (ABCSG-18): A multicentre, randomised, double-blind, placebo-controlled trial. Lancet. 2015; 386: 433-443.

63. Van Poznak C, Hannon RA, Mackey JR, Campone M, Apffelstaedt JP, Clack G, et al. Prevention of aromatase inhibitor-induced bone loss using risedronate: The SABRE trial. J Clin Oncol. 2010; 28: 967-975.

64. Sestak I, Singh S, Cuzick J, Blake GM, Patel R, Gossiel F, et al. Changes in bone mineral density at 3 years in postmenopausal women receiving anastrozole and risedronate in the IBIS-II bone substudy: An international, double-blind, randomised, placebo-controlled trial. Lancet Oncol. 2014; 15: 1460-1468.

65. Coleman R, Cameron D, Dodwell D, Bell R, Wilson C, Rathbone E, et al. Adjuvant zoledronic acid in patients with early breast cancer: Final efficacy analysis of the AZURE (BIG 01/04) randomised open-label phase 3 trial. Lancet Oncol. 2014; 15: 997-1006.

66. Black DM, Rosen CJ. Postmenopausal osteoporosis. N Engl J Med. 2016; 374: 254-262.

67. Cummings SR, Ferrari S, Eastell R, Gilchrist N, Jensen JB, McClung $M$, et al. Vertebral fractures after discontinuation of denosumab: A post hoc analysis of the randomized placebo-controlled FREEDOM trial and its extension. J Bone Miner Res. 2018; 33: 190-198.

68. Cheung AM, McKenna MJ, van de Laarschot DM, Zillikens MC, Peck V, Srighanthan J, et al. Detection of atypical femur fractures. J Clin Densitom. 2019; 22: 506-516.

69. Rodan GA, Fleisch HA. Bisphosphonates: Mechanisms of action. J Clin Invest. 1996; 97: 26922696.

70. Sato M, Grasser W, Endo N, Akins R, Simmons H, Thompson DD, et al. Bisphosphonate action. Alendronate localization in rat bone and effects on osteoclast ultrastructure. J Clin Invest. 1991; 88: 2095-2105.

71. Drake MT, Clarke BL, Khosla S. Bisphosphonates: Mechanism of action and role in clinical practice. Mayo Clin Proc. 2008; 83: 1032-1045.

72. Deeks ED, Perry CM. Zoledronic acid: A review of its use in the treatment of osteoporosis. Drugs Aging. 2008; 25: 963-986.

73. Black DM, Kelly MP, Genant HK, Palermo L, Eastell R, Bucci-Rechtweg C, et al. Bisphosphonates and fractures of the subtrochanteric or diaphyseal femur. N Engl J Med. 2010; 362: 1761-1771.

74. Miller PD. The kidney and bisphosphonates. Bone. 2011; 49: 77-81.

75. Liu J, Zheng LQ, Zhang WH, Chang KL, Pang Y. A modified method for reducing renal injury in zoledronic acid treatment of hypercalcemia and adverse skeletal events. Indian J Palliat Care. 2013; 19: 58-63.

76. Yarom N, Shapiro CL, Peterson DE, Van Poznak CH, Bohlke K, Ruggiero SL, et al. Medicationrelated osteonecrosis of the jaw: MASCC/ISOO/ASCO clinical practice guideline. J Clin Oncol. 2019; 37: 2270-2290. 
77. Gnant M, Pfeiler G, Steger GG, Egle D, Greil R, Fitzal F, et al. Adjuvant denosumab in postmenopausal patients with hormone receptor-positive breast cancer (ABCSG-18): Diseasefree survival results from a randomised, double-blind, placebo-controlled, phase 3 trial. Lancet Oncol. 2019; 20: 339-351.

78. Gnant $M$, Mlineritsch B, Stoeger $H$, Luschin-Ebengreuth $G$, Knauer M, Moik M, et al. Zoledronic acid combined with adjuvant endocrine therapy of tamoxifen versus anastrozol plus ovarian function suppression in premenopausal early breast cancer: Final analysis of the Austrian Breast and Colorectal Cancer Study Group Trial 12. Ann Oncol. 2015; 26: 313-320.

79. Josse R, Khan A, Ngui D, Shapiro M. Denosumab, a new pharmacotherapy option for postmenopausal osteoporosis. Curr Med Res Opin. 2013; 29: 205-216.

80. Hanley DA, Adachi JD, Bell A, Brown V. Denosumab: Mechanism of action and clinical outcomes. Int J Clin Pract. 2012; 66: 1139-1146.

81. Cummings SR, San Martin J, McClung MR, Siris ES, Eastell R, Reid IR, et al. Denosumab for prevention of fractures in postmenopausal women with osteoporosis. N Engl J Med. 2009; 361: 756-765.

82. De Sousa SM, Jesudason D. Rebound vertebral and non-vertebral fractures during denosumab interruption in a postmenopausal woman. Clin Endocrinol. 2019; 90: 250-252.

83. Lewiecki EM. New and emerging concepts in the use of denosumab for the treatment of osteoporosis. Ther Adv Musculoskelet Dis. 2018; 10: 209-223.

84. Levis S, Theodore G. Summary of AHRQ's comparative effectiveness review of treatment to prevent fractures in men and women with low bone density or osteoporosis: Update of the 2007 report. J Manag Care Pharm. 2012; 18: S1-S15.

85. Freemantle N, Cooper C, Diez-Perez A, Gitlin M, Radcliffe H, Shepherd S, et al. Results of indirect and mixed treatment comparison of fracture efficacy for osteoporosis treatments: A metaanalysis. Osteoporos Int. 2013; 24: 209-217.

86. Horikawa A, Miyakoshi N, Shimada Y, Sugimura Y, Kodama H. A comparative study between intravenous and oral alendronate administration for the treatment of osteoporosis. Springerplus. 2015; 4: 1-5.

87. Choi NK, Solomon DH, Tsacogianis TN, Landon JE, Song HJ, Kim SC. Comparative safety and effectiveness of denosumab versus zoledronic acid in patients with osteoporosis: A cohort study. J Bone Miner Res. 2017; 32: 611-617.

88. Adler RA, El-Hajj Fuleihan G, Bauer DC, Camacho PM, Clarke BL, Clines GA, et al. Managing osteoporosis in patients on long-term bisphosphonate treatment: Report of a task force of the American society for bone and mineral research. J Bone Miner Res. 2016; 31: 16-35.

89. Rizzoli R, Body JJ, DeCensi A, Reginster JY, Piscitelli P, Brandi ML, et al. Guidance for the prevention of bone loss and fractures in postmenopausal women treated with aromatase inhibitors for breast cancer: An ESCEO position paper. Osteoporos Int. 2012; 23: 2567-2576.

90. Canon JR, Roudier M, Bryant R, Morony S, Stolina M, Kostenuik PJ, et al. Inhibition of RANKL blocks skeletal tumor progression and improves survival in a mouse model of breast cancer bone metastasis. Clin Exp Metastasis. 2008; 25: 119-129.

91. Beuzeboc P, Scholl S. Prevention of bone metastases in Breast Cancer patients. Therapeutic perspectives. J Clin Med. 2014; 3: 521-536.

92. Shiozawa $\mathrm{Y}$, Eber MR, Berry JE, Taichman RS. Bone marrow as a metastatic niche for disseminated tumor cells from solid tumors. Bonekey Rep. 2015; 4: 689. 
93. Domschke C, Diel IJ, Englert S, Kalteisen S, Mayer L, Rom J, et al. Prognostic value of disseminated tumor cells in the bone marrow of patients with operable primary breast cancer: A long-term follow-up study. Ann Surg Oncol. 2013; 20: 1865-1871.

94. Aft R, Naughton M, Trinkaus K, Watson M, Ylagan L, Chavez-MacGregor M, et al. Effect of zoledronic acid on disseminated tumour cells in women with locally advanced breast cancer: An open label, randomised, phase 2 trial. Lancet Oncol. 2010; 11: 421-428.

95. Banys M, Solomayer EF, Gebauer G, Janni W, Krawczyk N, Lueck HJ, et al. Influence of zoledronic acid on disseminated tumor cells in bone marrow and survival: Results of a prospective clinical trial. BMC Cancer. 2013; 13: 1-9.

96. Coleman RE, Marshall H, Cameron D, Dodwell D, Burkinshaw R, Keane M, et al. Breast-cancer adjuvant therapy with zoledronic acid. N Engl J Med. 2011; 365: 1396-1405.

97. Paterson AH, Anderson SJ, Lembersky BC, Fehrenbacher L, Falkson Cl, King KM, et al. Oral clodronate for adjuvant treatment of operable breast cancer (National Surgical Adjuvant Breast and Bowel Project protocol B-34): A multicentre, placebo-controlled, randomised trial. Lancet Oncol. 2012; 13: 734-742.

98. Early Breast Cancer Trialists' Collaborative Group. Adjuvant bisphosphonate treatment in early breast cancer: Meta-analyses of individual patient data from randomised trials. Lancet. 2015; 386: 1353-1361.

99. Dhesy-Thind S, Fletcher GG, Blanchette PS, Clemons MJ, Dillmon MS, Frank ES, et al. Use of adjuvant bisphosphonates and other bone-modifying agents in Breast Cancer: A cancer care ontario and American society of clinical oncology clinical practice guideline. J Clin Oncol. 2017; 35: 2062-2081.

100.O'Carrigan B, Wong MH, Willson ML, Stockler MR, Pavlakis N, Goodwin A. Bisphosphonates and other bone agents for breast cancer. Cochrane Database Syst Rev. 2017; 10: CD003474.

101.Balic M, Thomssen C, Wurstlein R, Gnant M, Harbeck N. St. Gallen/Vienna 2019: A brief summary of the consensus discussion on the optimal primary Breast Cancer treatment. Breast Care. 2019; 14: 103-110.

102. Cardoso F, Kyriakides S, Ohno S, Penault-Llorca F, Poortmans P, Rubio IT, et al. Early breast cancer: ESMO clinical practice guidelines for diagnosis, treatment and follow-up. Ann Oncol. 2019; 30: 1194-1220.

103.Coleman R, Finkelstein DM, Barrios C, Martin M, Iwata H, Hegg R, et al. Adjuvant denosumab in early breast cancer (D-CARE): An international, multicentre, randomised, controlled, phase 3 trial. Lancet Oncol. 2020; 21: 60-72.

104.Gralow JR, Barlow WE, Paterson AH, M'lao JL, Lew DL, Stopeck AT, et al. Phase III randomized trial of bisphosphonates as adjuvant therapy in Breast Cancer: S0307. J Natl Cancer Inst. 2020; 112: 698-707.

105.Saag KG, Petersen J, Brandi ML, Karaplis AC, Lorentzon M, Thomas T, et al. Romosozumab or alendronate for fracture prevention in women with osteoporosis. N Engl J Med. 2017; 377: 1417-1427.

106.Chavassieux P, Chapurlat R, Portero-Muzy N, Roux JP, Garcia P, Brown JP, et al. Bone-forming and antiresorptive effects of romosozumab in postmenopausal women with osteoporosis: Bone histomorphometry and microcomputed tomography analysis after 2 and 12 months of treatment. J Bone Miner Res. 2019; 34: 1597-1608. 
107. Nakai Y, Okamoto K, Terashima A, Ehata S, Nishida J, Imamura T, et al. Efficacy of an orally active small-molecule inhibitor of RANKL in bone metastasis. Bone Res. 2019; 7: 1-10.

108. Pisani P, Renna MD, Conversano F, Casciaro E, Di Paola M, Quarta E, et al. Major osteoporotic fragility fractures: Risk factor updates and societal impact. World J Orthop. 2016; 7: 171-181.

109.Tremblay D, Patel V, Fifer KM, Caro J, Kolodka O, Mandelli J, et al. Management of bone health in postmenopausal women on aromatase inhibitors (Als): A single health care system experience. Support Care Cancer. 2018; 26: 197-202.

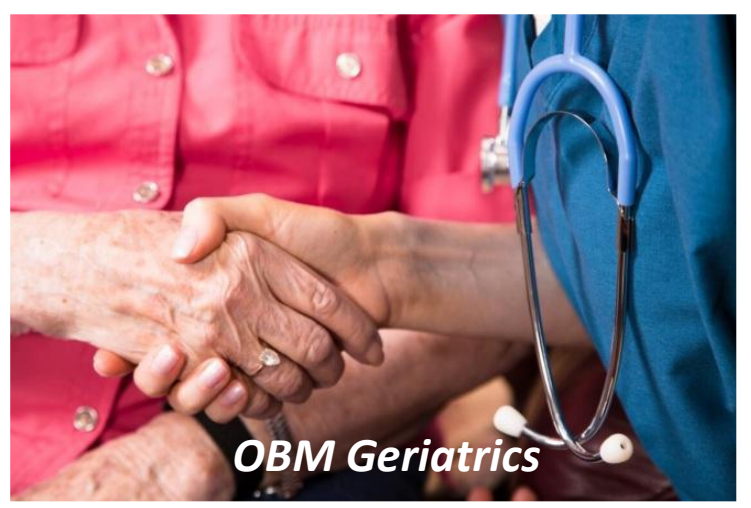

Enjoy $O B M$ Geriatrics by:

1. Submitting a manuscript

2. Joining in volunteer reviewer bank

3. Joining Editorial Board

4. Guest editing a special issue

For more details, please visit:

http://www.lidsen.com/journals/geriatrics 